\title{
Particle size of yam flour and its effects on physicochemical properties and bioactive compounds
}

\author{
Zhaogen $\mathrm{WU}^{1 *}$, Kashif AMEER ${ }^{2,3,4 *}\left(\mathbb{D}\right.$, Chengchen $\mathrm{HU}^{1}$, Annuo $\mathrm{BAO}^{1}$, Rong WANG ${ }^{1}$, Wei TANG ${ }^{1}$, \\ Neelam CHAUDHARY ${ }^{5}$, Guihun JIANG ${ }^{1 *}$ (D)
}

\begin{abstract}
Chinese yam (Rhizoma Dioscoreas Oppositae) has been recorded in Traditional Chinese Medicine and is utilized as a common food delicacy in China. This study was carried out to evaluate effects of superfine grinding at variable mesh sizes on physicochemical, thermal, microstructural attributes, bioactive compounds and radical scavenging activities (RSA's) of yam flour powders (YFP). Physical, color, hydration, total phenolic, flavonoid contents, RSA's and absorption characteristics were significantly influenced by exhibiting increasing trends with reduction of YFP particle sizes. YFP fraction obtained at M400 size showed obviously improved specific surface area as compared to M60 fraction. Generally, it may be implied from the results that free-form phenolic compounds exhibited increasing trends whereas cell-wall bound phenolic compounds showed particle size-dependent decreases with corresponding increases in mesh size. ESEM micrographs endorsed the finding of reduction of YFP particle sizes with corresponding increases in sieve mesh sizes. ESEM analysis evidently showed that mechanical shear significantly led to enhancement of surface area. Differential scanning calorimetry showed that melting temperature of YFP with reduced particle size were lower. Conclusively, it may be implied that YFP superfine powders might be utilized in food formulations with improved functional properties and uniformity.
\end{abstract}

Keywords: Chinese yam; powder; superfine grinding; color; physicochemical.

Practical application: Superfine powders of reduced particles sizes can be used as novel food ingredients in food product development.

\section{Introduction}

Globally, almost 600 species of yam (Dioscorea spp.) have been reported and 93 out of all are usually originated from China. Chinese yam (Rhizoma Dioscoreas Oppositae) is not only employed as a common food delicacy in China, but, it has also been classified in the Traditional Chinese Medicine for treating various ailments, such as diarrhea, diabetes, asthma, improvement of stomach function and alleviation of anorexia etc. (Chen et al., 2015; Ju et al., 2014). In China, am is usually produced in Shandong, Shanxi and Hebei provinces whereas, Xinxiang county of Henan province is best known for high-quality yam production. Winter season is the harvesting period of yam and postharvest procedures involve washing, peeling, sulfur steaming, drying, softening and slicing (Shujun et al., 2008; Yang et al., 2015). Chinese yam tuber are aso reported to consist of $5.51 \%$ ash and various minerals like potassium $(2.26 \%)$, phosphorus $(0.2 \%)$, calcium $(0.2 \%)$, magnesium $(0.14 \%)$, iron $(53.6 \mathrm{mg} / \mathrm{kg})$, zinc $(29.2 \mathrm{mg} / \mathrm{kg})$, copper $(10.6 \mathrm{mg} / \mathrm{kg})$ and manganese $(5.38 \mathrm{mg} / \mathrm{kg}$ ) (Shujun et al., 2008). Chinese yam comprises of several chemical components in its composition, such as batatasine, allantoin, saponins, campesterol, ergosterol, choline, glucoprotein, amino acids, abscisin II, phytic acid, dopamine, starch and non-starch polysaccharides etc. which have been widely studies in previously published reports (Li et al., 2019a; Shujun et al., 2008). Chinese yam has also been shown to exhibit potent antioxidant activity and yam polysaccharides have been reported to have various pharmacological activities, such as immunity boosting, antibacterial and serum glucose lowering effects (Jeon et al., 2006).

In recent years, superfine grinding has been employed as novel method for developing functional food products. As compared to powder products obtained through conventional means, superfine powders have been to contain improved functional properties, such as mechanical, catalytic optical, magnetic characteristics accompanied by presence of mini-sized macro-quantum channels and enhanced surface properties (Huang et al., 2018). Furthermore, superfine powder products exhibit increase suitability with regard to preparation of instant and convenient foods owing to improved functional characteristics, such as oil and water holding capacities, increased solubility and alternations 
to microstructural attributes (Wu et al., 2021). Recently, it has also been reported that superfine grinding influence antioxidant compounds in terms of increasing tendencies which might be attributable to the fact of modifications of molecular weight of bioactive component and solublization behavior ( $\mathrm{Li}$ et al., 2020 b). Previously reported studies on yam have investigated the health functionalities, chemical composition (Chen et al., 2015), and characterization of Chinese yam (Yang et al., 2015; Shujun et al., 2008) as well as effect of drying methods on physicochemical and pasting properties of yam flour (Li et al., 2019a), however to the best of our knowledge, reports regarding superfine grinding effect on physicochemical properties and antioxidant compounds of yam flour are still lacking. Therefore, the aim of this study was to evaluate effects of various particle size distributions on physicochemical, thermal, microstructural properties, racial-scavenging activities and bioactive compounds of Chinese yam flour. This study will provide the beneficial information for food, feed, pharmaceutical and nutraceutical industries to prepare active food ingredients using superfine yam powder product.

\section{Materials and methods}

\subsection{Materials}

Yam was purchased from a local supermarket of Jillin, China. All chemicals and reagents used in this study were of analytical grade.

\subsection{Yam Flour Powder (YFP) preparation at variable particle sizes}

Milling of peeled yam was carried out in coarse manner using a disc-mill (FZ102, Taisite Instrument Co., Ltd., Tianjin, China), and then sieving of powders was performed by passing through 60-100, 100-160 and 160-200 mesh sieves to obtain three variable fractions based on particle size. Superfine powdered fractions were passed through mesh size in range of 200-400 mesh and powders lower than 400 mesh size were prepared using a superfine mill (HMB-700S, Hongquan Machinery Co., LTD, Taipei, Taiwan) by regulating the grinding time. Particle size of samples between 60 and 100 mesh, 100 and 160-mesh, 160 and 200 mesh, 200-400 mesh and less than 400-mesh were named M60, M100, M160, M200 and M400. All samples were sealed in aluminum-laminated bags and stored at $-20^{\circ} \mathrm{C}$ until further use.

\subsection{Particle size and microstructure}

Particle size distributions of the YFP were analyzed by a Matersizer 3000 laser diffraction instrument (Malvern Instruments Co., Ltd., Malvern, UK). The powder was dispersed in water prior to measurements. YFP morphology was observed using an environmental scanning electron microscopy (ESEM, Quanta 250 FEG, FEI, Hillsborough, OR, USA). YFP samples were coated with gold, attached to a double-sided adhesive tape, and observed at $600 \times$ magnification.

\subsection{Bulk density, tap density, and flowability}

The bulk and tapped densities of the YFP samples were measured according to the method described by Ramachandraiah \& Chin (2017). The flowability of the samples were evaluated by the Carr index (\%) (Carr, 1965). The Carr index was calculated as shown in Formula 1, below:/

Carr index $(\%)=[($ Tap density - Bulk density $) /$ Tap density $] \times 100$

Samples with Carr index values ranging from 0 to $15 \%$ were considered as having good flowability, from 15-25\% as having fair flowability, $25-30 \%$ as having poor flowability, and values over $30 \%$ as having very poor flowability (Muttakin et al., 2015).

\subsection{Color values}

SFP samples of color properties ( $L^{*}, a^{*}$ and $b^{*}$ values) were measured by colorimeter (CM-3600A, Konica Minolta, Osaka, Japan). The calibration of the equipment was performed by a white tile prior to recording sample color values and standard values were these: $L^{*}=86.90, a^{*}=0.3170$, and $b^{*}=0.3240$.

\subsection{Hydration and adsorption properties}

Water holding capacity (WHC) and water solubility index (WSI) were determined as per the Phat et al. (2015) method. For WHC quantification, $0.5 \mathrm{~g}(\mathrm{H})$ of sample was added to $10 \mathrm{~mL}$ of distilled water followed by mixing in a $15 \mathrm{~mL}$ centrifuge tube $\left(\mathrm{W}_{1}\right)$. Afterwards, the reaction mixture was subjected to incubation in a water bath (DK-500, Jing Hong Laboratory Instrument Co., Ltd., Shanghai, China) at $60^{\circ} \mathrm{C}$ for $30 \mathrm{~min}$ and subsequently centrifugation at $3000 \mathrm{rpm}$ for $15 \mathrm{~min}$ (TD5A-WS, Xianglu Centrifuge Apparatus Co., Ltd., Changsha, China). Then the sediment tubes were weighed $\left(\mathrm{W}_{2}\right)$. WHC was then calculated based on the Formula 2:

$W H C(g / g)=\left(W_{2}-W_{1}\right) / H$

For WSI quantification, about $10 \mathrm{~mL}$ of distilled water was mixed in a tube having $0.2 \mathrm{~g}$ of powder, which was further placed in a water bath at $80^{\circ} \mathrm{C}$ for $30 \mathrm{~min}$. After centrifugation at $3000 \mathrm{rpm}$ for $10 \mathrm{~min}$ ), the supernatant was transferred to a pre-weighed dish $\left(\mathrm{S}_{1}\right)$ and dried at $105^{\circ} \mathrm{C}$ to constant weight $\left(\mathrm{S}_{2}\right)$. WSI was then calculated using the Formula 3:

$\operatorname{WSI}(\%)=\left(S_{2}-S_{1}\right) / S$

Oil holding capacity (OHC) of samples ( $1 \mathrm{~g}$ each) were measured by mixing with $25 \mathrm{~mL}$ sunflower oil for $18 \mathrm{~h}$ at room temperature and centrifugation at $3500 \mathrm{rpm}$ for $20 \mathrm{~min}$. OHC was expressed as the weight of oil absorbed per gram of sample (Abdul-Hamid \& Luan, 2000).

\subsection{Crude saponin contents}

Crude saponin contents were determined according to the water-saturated n-butanol extraction method of Park et al. (2012) with some modification. Each of SFP ( $4 \mathrm{~g}$ ) samples was taken in heat reflux extractor and heated at $70{ }^{\circ} \mathrm{C}$ for $12 \mathrm{~h}$ using $70 \%$ ethanol $(80 \mathrm{~mL})$ followed by filtration through Whatman No.1 filter paper (Whatman Ltd., Cambridge, UK) and concentration at $50^{\circ} \mathrm{C}$. Rotary evaporation was performed for resulting extract to evaporate $\mathrm{n}$-butanol layer at $50{ }^{\circ} \mathrm{C}$. The, evaporated residue was dried at $105^{\circ} \mathrm{C}$ until constant weight attainment. 
Evaporated residue weight was measured which was indicative of crude saponin content.

\subsection{Preparation of phenolic extracts}

The YFP samples were extracted according to a method by Jiang et al. (2018). Homogenization and sonication treatments were performed repeatedly followed by filtration with a No 1 . filter paper (Whatman Ltd., Cambridge, UK). The supernatant of each sample was collected, concentrated in vacuum, and stored at $-20^{\circ} \mathrm{C}$ for future use total phenolic content (TPC), total flavonoid content (TFC), and antioxidant activities.

\subsection{TPC}

In order to determine TPC content, each SFP sample was processed according to method of Eghdami \& Sadeghi (2010). Folin-Ciocalteu reagent method was employed. Diluted extract $(200 \mu \mathrm{L})$ was added to $800 \mu \mathrm{L}$ Folin-Ciocalteu reagent in combination with $2 \mathrm{~mL}$ sodium carbonate (7.5\%). After mixture dilution with distilled water prior to incubation, the reaction mixture was allowed to stand at ambient temperature $\left(23 \pm 2{ }^{\circ} \mathrm{C}\right)$ under darkness for $2 \mathrm{~h}$. A UV spectrophotometer (UV-1800, Shimadzu Instruments Mfg. Co., Ltd., Kyoto, Japan) was employed for determining absorbance values at $765 \mathrm{~nm}$. The TPC was expressed as gallic acid equivalents (mg GAE $100 \mathrm{~g}^{-1}$ ) on dry weight (DW) basis.

\subsection{TFC}

Colorimetric method on basis of aluminum nitrate was utilized to determine TFC as per method of Eghdami \& Sadeghi (2010). Sample extract of $1 \mathrm{~mL}$ was mixed with $3 \mathrm{~mL}$ distilled water followed by the addition of $0.3 \mathrm{~mL}$ of $5 \% \mathrm{NaNO}_{2}$. Reaction mixture was provided standing time of $5 \mathrm{~min}$ at $25^{\circ} \mathrm{C}$ and then addition of $0.3 \mathrm{~mL}$ of $10 \% \mathrm{AlCl}_{3}$ was carried out. After $5 \mathrm{~min}$, the reaction mixture was mixed with $2 \mathrm{~mL}$ of $1 \mathrm{M} \mathrm{NaOH}$. Afterwards, addition of distilled water in an amount of $10 \mathrm{~mL}$ was performed to the reaction mixture followed by absorbance measurement at $510 \mathrm{~nm}$ against rutin as a standard, and results were represented as milligram rutin equivalent ( $\mathrm{mg}$ RE $100 \mathrm{~g}^{-1}$ ) on DW basis.

\subsection{Thermal properties analysis}

The thermal property analysis of the SFP was carried out using a differential scanning calorimeter (Netzsch, MicroCal DSC, Cph60, Germany). About 10-20 mg of sample was used and then thermograms were recoded from 20 to $200{ }^{\circ} \mathrm{C}$ at a heating rate of $10^{\circ} \mathrm{C} / \mathrm{min}$ in a $20 \mathrm{~mL} / \mathrm{min}$ nitrogen flow against reference which was empty aluminum pan. Triplicate measurements were recorded.

\subsection{Statistical analysis}

All values were presented as mean \pm standard deviation. One-way analysis of variance (ANOVA) was used to determine differences between treatments and were carried out in SPSS version 18.0 (Chicago, IL, USA). Significance was determined by Duncan's multiple-range test at $p<0.05$.

\section{Results and discussion}

\subsection{Particle size distribution}

Laser particle size analyzer was employed to determine particle size distributions (PSDs) of Yam Flour Powder (YFP) and results are given in Table 1. PSD's of all YFP fractions (M60, M100, M160, M200 and M400) were determined at volume distributions of $\mathrm{D}(10) / \mu \mathrm{m} \mathrm{D}(50) / \mu \mathrm{m}$ and $\mathrm{D}(90) / \mu \mathrm{m}$, Whereas, D (10), D (50) and D (90) represented quantities of YFP particles those were smaller (i.e., $10 \%, 50 \%$, and 90\%) than average particulate sizes in flour samples. Overall, it was evident from results that YFP exhibited decreasing tendency in diameters ( $\mathrm{Dv} 10,50$ and 90$)$ with corresponding rises in mesh screen numbers. In case of M400 YFP fraction, the Dv 10, 50 and 90 values were $8.24,25.70$ and $48.95 \mu \mathrm{m}$, respectively. In case of powder products used in food preparation, high degree of solubility and dispersibility is observed in powders having smaller and finer particle sizes. However, span values showed slightly decreasing tendency with rises in mesh sizes from M60 to M160, whereas further rise in mesh screen sizes from M200 to M400 caused significant rises in span values, suggested wider PSDs in yam flour. Particles sizes at Dv 10,50 and 90 for all mesh sizes ranged 8.24-175 $\mu \mathrm{m}, 25.70-321 \mu \mathrm{m}$ and $32.35-450.55 \mu \mathrm{m}$, respectively, whereas span values of YFP fractions at all mesh sizes were in range of 0.83-159. Moreover, specific surface area (SAA) was also measured for all flour fractions as shown in Table 1. YFP fraction obtained at M400 size showed obviously improved SAA in comparison with YFP fraction obtained through routine grinding (M60). Improved SAA is also reported to have close linkage to improved adsorption capacity and may lead to increased degree of solubility of powdered granules and samples (Wu et al., 2021). Moreover, YFP with increased SSA may render faster solubilization of bioactive and function ingredient accompanied by enhanced absorption and bioavailability. Therefore, it may be inferred that powders with high degree of

Table 1. Particle size distribution of Yam Flour (YF) with different particle size.

\begin{tabular}{|c|c|c|c|c|c|}
\hline & $\begin{array}{c}\text { Dv }(10) \\
(\mu \mathrm{m})\end{array}$ & $\begin{array}{c}\mathrm{Dv}(50) \\
(\mu \mathrm{m})\end{array}$ & $\begin{array}{c}\text { Dv }(90) \\
(\mu \mathrm{m})\end{array}$ & $\begin{array}{c}\text { Specific Surface Area } \\
\left(\mathrm{m}^{2} / \mathrm{kg}\right)\end{array}$ & Span \\
\hline M60 & $175.50 \pm 9.19 a$ & $321.00 \pm 8.49 a$ & $480.00 \pm 12.73 a$ & $65.10 \pm 3.57 \mathrm{~b}$ & $0.95 \pm 0.01 b$ \\
\hline M100 & $126.50 \pm 0.71 b$ & $197.00 \pm 1.41 b$ & $300.50 \pm 0.71 b$ & $32.35 \pm 0.18 \mathrm{~d}$ & $0.88 \pm 0.01 b$ \\
\hline M160 & $89.65 \pm 0.21 c$ & $134.00 \pm 0.01 c$ & $200.00 \pm 1.41 c$ & $46.88 \pm 0.20 c$ & $0.83 \pm 0.01 b$ \\
\hline M200 & $54.00 \pm 0.57 \mathrm{~d}$ & $112.00 \pm 2.83 d$ & $216.50 \pm 13.44 c$ & $62.82 \pm 1.58 b$ & $1.45 \pm 0.08 \mathrm{a}$ \\
\hline M400 & $8.24 \pm 0.25 \mathrm{e}$ & $25.70 \pm 0.28 \mathrm{e}$ & $48.95 \pm 4.03 \mathrm{~d}$ & $450.55 \pm 3.18 \mathrm{a}$ & $1.59 \pm 0.15 a$ \\
\hline
\end{tabular}

Values are means \pm standard deviation of triplicate determinations; a-e Means followed by different letters in a column are significantly different $(p<0.05)$. 
SSA have great potential to be utilized as desirable food additives or materials by the industrial food manufacturers.

\subsection{Effect of superfine grinding on physical properties}

Results of physical properties such as color values, bulk density, tapped density, and Carr index at variables particle sizes are given in Table 2. At all mesh sizes, YFP exhibited bulk densities and tapped densities ranged $0.52-0.67 \mathrm{~g} / \mathrm{cm}^{3}$ and $0.74-0.82 \mathrm{~g} / \mathrm{cm}^{3}$, respectively. Evidently, it was implied from the results that as the powder mesh sizes was increased from M60 to M400, both bulk and tapped densities showed significantly declining tendencies. Wu et al. (2021) and Cao et al. (2018) also reported findings similar to those reported in this study. On the other hand, Carr index is also one of the quality parameters for assessing flowability of powdered products for quality assurance purposes. It was found that Carr index was increased with corresponding increases in particle mesh sizes (from M60 to M400) and was found to be ranged 19.03-30.81\% for all YFP samples. This findings implied that gradual rises in mesh sizes led to obtainment of YFP powder product with lower degree of flowability including M60 (Carr index: 19.03\%), to fair degree of flowability for M160 (Carr index: 29.97\%) and M400 (Carr index: $30.81 \%$ ). Lower Carr index values were indicative of the fact that intact YFP powders exhibited strong cohesiveness which may possibly cause handling difficulty for these powder products. These results were in agreement with the previously reported findings of Wu et al. (2021) and Quispe-Condori et al. (2011). Moreover, it has already been reported that powder product processing involving mixing, sieving and pouring must take into account Carr index values (Muttakin et al., 2015).

Hunter color values of YFP powder at variable particle sizes were also evaluated and results are tabulated in Table 2. It was found that both $L^{*}$ and $b^{*}$ values remained invariably same whereas $L^{*}$ values exhibited slightly increasing (from 82.73 to 90.24) with corresponding increases in mesh sizes from M60 to M400. However, $a^{\star}$ values remained same for M60, M100 and M160 samples but further rises in mesh sizes caused significant decreases in $a^{\star}$ values (degree of redness/greenness). Moreover, degree of yellowness ( $b^{*}$-values) also showed decreasing trend with increases in YFP particle sizes. This implied that superfine grinding led to achieve powder products with high degree of lightness and reduced degree of redness and yellows. Decreases in degrees of yellowness and redness could be ascribed to the possible aggregation phenomenon of phenolic compounds as well as superfine grinding-induced degradation of chlorophyll in YFP powder products. These results were similar to the previously reported findings of Hu et al. (2012), whereby gradual decreases in particle sizes caused corresponding decline in degrees of redness and yellowness in green tea powders.

\subsection{Absorption and hydration properties}

Water holding (WHC) and oil holding capacities (OHC) as well water solubility index (WSI) usually serve as the measure of absorption and hydration properties of powder products. WHC, $\mathrm{OHC}$ and WSI were calculated for YFP powders of variable particle sizes and results are given in Table 2. WHC and $\mathrm{OHC}$ showed increased tendencies in ranges of 2.09-7.15 g/g and 2.65-3.31 g/g, respectively with corresponding decreases in particle sizes. Degrees of coarseness and fineness of powder products serve as significant determinants of WSI and OHC, whereas wider interstitial spaces are found in case of coarse powder products as compared to fine powders. Increases in WSI of YFP superfine powders could be attributed to the fact of gradual rises in surface areas of superfine powders which caused increased tendency in solid matrix particles to interact with that of solvent. At all particle sizes, WSI was found to be in range of $45-60 \%$ which implied that superfine grinding of YFP powders exerted significant effect $(p<0.05)$ on solubilization ability of powder products with variable PSDs. Moreover, it was also evident from results that superfine powder exhibited enhanced degree of dissolution of soluble powder components owing to high solvent penetration through solid particles matrices. The results of this study were in conformance with the findings reported by Zhao et al. (2010) and Wu et al. (2021). Surface properties of YFP powder were significantly affected after exposure to superfine grinding which caused certain modification in powder characteristics like increased tendencies in surface area and energy. Powder porosity also exert influence on hydration behavior hence, it may be inferred that porosity of YFP powders were enhanced after grinding at variable PSDs which consequently causes rises in hydration followed by diffusion and bioavailability of YFP powders (Wu et al., 2021; Zhao et al., 2010).

\subsection{Quantified phenolic compounds of superfine YFP fractions}

All YFP superfine fractions at variable particle sizes (M60, M100, M160, M200 and M400) were analyzed for individual phenolic compounds and results of quantified phenolic acids

Table 2. Physical, hydration, and adsorption properties and of Yam Flour (YF) with different particle size.

\begin{tabular}{|c|c|c|c|c|c|c|c|c|c|}
\hline \multirow{2}{*}{$\begin{array}{l}\text { Mesh } \\
\text { Size }\end{array}$} & \multirow{2}{*}{$\begin{array}{l}\text { Bulk density } \\
\qquad\left(\mathrm{g} / \mathrm{cm}^{3}\right)\end{array}$} & \multirow{2}{*}{$\begin{array}{c}\text { Tapped } \\
\text { density ( } \mathrm{g} / \\
\left.\mathrm{cm}^{3}\right)\end{array}$} & \multirow{2}{*}{$\begin{array}{c}\text { Carr index } \\
(\%)\end{array}$} & \multirow[b]{2}{*}{ WHC (g/g) } & \multirow[b]{2}{*}{ WSI (\%) } & \multirow[b]{2}{*}{$\mathrm{OHC}(\mathrm{g} / \mathrm{g})$} & \multicolumn{3}{|c|}{ Color values } \\
\hline & & & & & & & $L^{*}$ & $a^{*}$ & $b^{*}$ \\
\hline M60 & $0.67 \pm 0.02 \mathrm{a}$ & $0.82 \pm 0.01 \mathrm{a}$ & $19.03 \pm 0.83 b$ & $2.09 \pm 0.13 b$ & $45.00 \pm 0.00 b$ & $2.65 \pm 0.18 b$ & $82.73 \pm 0.11 d$ & $0.78 \pm 0.08 a$ & $12.79 \pm 0.22 \mathrm{a}$ \\
\hline M100 & $0.56 \pm 0.01 b$ & $0.78 \pm 0.02 b$ & $28.04 \pm 2.63 a$ & $2.95 \pm 0.01 b$ & $\begin{array}{c}50.00 \pm \\
7.07 \mathrm{ab}\end{array}$ & $2.79 \pm 0.22 b$ & $84.58 \pm 0.85 c$ & $0.78 \pm 0.03 a$ & $11.73 \pm 0.66 b$ \\
\hline M160 & $0.54 \pm 0.01 c$ & $0.77 \pm 0.01 b c$ & $29.97 \pm 1.38 \mathrm{a}$ & $3.58 \pm 0.11 b$ & $\begin{array}{c}52.50 \pm \\
3.54 \mathrm{ab}\end{array}$ & $2.84 \pm 0.10 b$ & $87.39 \pm 0.20 b$ & $0.78 \pm 0.05 a$ & $9.70 \pm 0.35 c$ \\
\hline M200 & $0.53 \pm 0.01 \mathrm{~cd}$ & $0.75 \pm 0.02 b c$ & $30.37 \pm 2.05 a$ & $6.8 \pm 1.58 \mathrm{a}$ & $\begin{array}{c}52.50 \pm \\
3.54 \mathrm{ab}\end{array}$ & $2.85 \pm 0.14 b$ & $87.62 \pm 0.74 b$ & $0.47 \pm 0.04 b$ & $8.43 \pm 0.47 d$ \\
\hline M400 & $0.52 \pm 0.01 \mathrm{~d}$ & $0.74 \pm 0.01 c$ & $30.80 \pm 1.14 a$ & $7.15 \pm 0.07 a$ & $60.00 \pm 7.07 a$ & $3.30 \pm 0.31 \mathrm{a}$ & $90.24 \pm 0.09 a$ & $0.17 \pm 0.01 c$ & $6.80 \pm 0.06 \mathrm{e}$ \\
\hline
\end{tabular}

Values are means \pm standard deviation of triplicate determinations; a-d Means followed by different letters in a column are significantly different $(p<0.05)$. 
were provided in Table 3. Excluding epicatechin, coumaric acid, quercetin and cinnamic acid, all other phenolic acids showed increasing tendencies in YFP powder obtained through M100 mesh size. Whereas further particle size reduction in YFP powders at mesh sizes of M160, M200 and M400 caused size-dependent deceasing tendencies in concentrations of all phenolic acids. M100 exhibited the highest quantities of chlorogenic acid $(12.46 \mathrm{mg} / \mathrm{g})$, clove acid $(6.11 \mathrm{mg} / \mathrm{g})$, catechins $(2.73 \mathrm{mg} / \mathrm{g})$, ferulic acid $(4.23 \mathrm{mg} / \mathrm{g})$, ellagic acid $(9.65 \mathrm{mg} / \mathrm{g})$ and resveratrol $(4.74 \mathrm{mg} / \mathrm{g})$ and led to significant rises of approximately $466.36 \%, 4.67 \%$, $20.81 \%, 18.82 \%, 2 \%$, and 1.94 , respectively. Only in case of ellagic acid, highest amount $(10.36 \mathrm{mg} / \mathrm{g})$ was achieved in YFP fraction obtained through M160 mesh and showed gradually rising trend with corresponding increase in mesh size from M60 to M160. Whereas, chlorogenic acid and catechins exhibited gradual rises in their concentrations with corresponding reduction in particle sizes. Phenolic compounds usually exist in plant matrices in free and cell-wall bound forms. Generally, it may be implied from the results that free-form phenolic compounds exhibited increasing trends whereas cell-wall bound phenolic compounds showed particle size-dependent decreases with corresponding increases in mesh size of superfine YFP powders. This could be possibly attributable to the partial cellular degradation upon particle size reduction as well as aggregation phenomenon of phenolics with rises in ball-milling times (Augusto-Obara et al., 2019). Moreover, cell-wall bound secondary metabolites in plant matrices usually occur in form of covalent linkages to other plant cellular components like cellulose, pectin, polysaccharides and macromolecules etc. Several published studies have ascertained that phenolic compounds free and cell-wall bound form are subjected to modification owing to processing-induced enhanced cell-wall degradation (Meng et al., 2019; Li et al., 2020b).

\subsection{Monosaccharides composition of superfine YFP powders}

Carbohydrate compounds including mannose, glucose, galactose and xylose were evaluated in all YFP fractions and results are given in Table 4. Mannose content decreased with corresponding reduction in particle sizes from M60 to M400 and was ranged 3.11-5.23 mg/g. M100 and M160 mesh sizes led to significant decreases in mannose content whereas, YFP powder obtained at M400 size showed comparable mannose content to that of M60 YFP fraction. M200 fractions comprised of highest mannose $(5.22 \mathrm{mg} / \mathrm{g})$ and glucose contents $(9.14 \mathrm{mg} / \mathrm{g})$. Similarly, in case of glucose, size-dependent decreasing trend in glucose was evident from the results and M60 and M200 fractions exhibited comparable glucose contents ranged 7.61-9.14 mg/g. Superfine grinding also exerted influence on galactose content which ranged $1.67-2.03 \mathrm{mg} / \mathrm{g}$. Overall slightly decreasing tendency was observed in galactose content of all YFP fractions with corresponding reduction of particle sizes from M60 to M400. Conversely, xylose content was found to be invariably same in all YFP powder fractions. Increased monosaccharide concentrations of mannose and glucose at M200 YFP fraction might be ascribed to the fact that superfine grinding-induced pulverization caused cell-wall breakdown followed by subsequent release and dissolving of glucose and mannose of plant cell wall matrix. Similar results have been reported by Li et al. (2019b) for monosaccharides compositions of superfine Phellinus baumii powder.

\subsection{Effects of superfine grinding on microstructure}

ESEM microscopy was carried for all YFP superfine particle distributions and results are demonstrated in terms of micrographs in Figure 2a. ESEM micrographs provided detailed overview about internal matrices and porosity of YFP powders. ESEM micrographs endorsed the finding of reduction of YFP particle sizes with corresponding increases in sieve mesh sizes. ESEM analysis evidently showed that mechanical shear significantly influenced surface area owing to particles breakdown which consequently led to enhanced surface area after exposure to superfine pulverization. This grinding-induced pulverization effect caused particles disintegration and YFP granules fragmentation. Moreover, it was observed that initial phases of superfine grinding exhibited lower rate of particle size reduction, however, as the superfine grinding proceeded, the particles size reduction showed gradually steady trend. Lower particle size reduction during initialization of superfine grinding might be attributable to the particles aggregation in tightly-packed manner. Superfine grinding caused shear breakdown of intermolecular linkages which caused mechanical damage followed by conversion of structural configuration from ordered state to high degree of amorphousness (Zhao et al., 2015a). Furthermore, as the mesh sizes increased to M400, the YFP powders showed enhanced breakdown to smaller granules owing to fractionation. Superfine pulverization caused induction of flattening, aggregation and fracture which led to significant shape variability in YFP powdered granules. It may be implied that high degree of superfine grindinginduced variability observed in YFP powder fractions might cause changes in functional and physiochemical characteristics of powder products (Wu et al., 2021). At initial phases of fracturing cracking of particulate granules, the aggregation phenomenon led to achieve increased sizes at start, while further rises in pulverization effect of superfine grinding causes severe particle size reductions (Zhao et al., 2015b). Conclusively, it could be inferred that all powder products obtained at variable particle sizes exhibited significant morphological variations

Table 3. Phenolic compounds of Yam Flour (YF) with different particle size.

\begin{tabular}{|c|c|c|c|c|c|c|c|c|c|c|}
\hline $\begin{array}{l}\text { Mesh } \\
\text { Size }\end{array}$ & $\begin{array}{c}\text { Chlorogenic } \\
\text { acid }\end{array}$ & Syringic acid & Epicatechin & Catechins & $\begin{array}{c}p \text {-Coumaric } \\
\text { acid }\end{array}$ & Ferulic acid & Ellagic acid & Quercetin & Resveratrol & $\begin{array}{c}\text { Cinnamic } \\
\text { acid }\end{array}$ \\
\hline M60 & $2.20 \pm 0.03 e$ & $5.83 \pm 0.44 a b$ & $1.44 \pm 0.03 a$ & $2.26 \pm 0.03 c$ & $5.71 \pm 0.18 a$ & $3.56 \pm 0.06 c$ & $9.46 \pm 0.03 b$ & $2.92 \pm 0.28 \mathrm{a}$ & $4.65 \pm 0.21 a$ & $11.20 \pm 0.82 \mathrm{a}$ \\
\hline M100 & $12.46 \pm 0.08 \mathrm{a}$ & $6.10 \pm 0.01 \mathrm{a}$ & $1.14 \pm 0.06 \mathrm{~b}$ & $2.73 \pm 0.04 b$ & $4.19 \pm 0.13 b$ & $4.23 \pm 0.01 \mathrm{a}$ & $9.65 \pm 0.01 \mathrm{ab}$ & $2.63 \pm 0.01 a$ & $4.74 \pm 0.00 \mathrm{a}$ & $8.42 \pm 0.01 b$ \\
\hline M160 & $8.27 \pm 0.01 c$ & $5.69 \pm 0.01 \mathrm{ab}$ & $1.08 \pm 0.03 b c$ & $2.05 \pm 0.01 d$ & $4.07 \pm 0.01 b$ & $3.65 \pm 0.01 b$ & $10.36 \pm 0.03 a$ & $2.17 \pm 0.24 b$ & $4.4 \pm 0.01 b$ & $4.80 \pm 0.74 c$ \\
\hline M200 & $9.38 \pm 0.14 b$ & $5.56 \pm 0.03 \mathrm{ab}$ & $1.05 \pm 0.01 \mathrm{c}$ & $2.11 \pm 0.01 d$ & $4.09 \pm 0.01 b$ & $3.58 \pm 0.01 b c$ & $10.19 \pm 0.69 \mathrm{ab}$ & $2.01 \pm 0.01 b$ & $4.38 \pm 0.03 b$ & $4.20 \pm 0.03 c$ \\
\hline M400 & $5.06 \pm 0.42 \mathrm{~d}$ & $5.06 \pm 0.71 b$ & - & $2.89 \pm 0.01 \mathrm{a}$ & $4.04 \pm 0.01 b$ & $2.35 \pm 0.01 d$ & $8.13 \pm 0.04 c$ & - & - & $4.62 \pm 0.01 c$ \\
\hline
\end{tabular}

Values are means \pm standard deviation of triplicate determinations; a-d Means followed by different letters in a column are significantly different $(p<0.05)$. 
Table 4. Monosaccharide composition of Yam Flour (YF) with different particle size.

\begin{tabular}{lcccc}
\hline $\begin{array}{c}\text { Mesh } \\
\text { Size }\end{array}$ & Man & Glu & Gal & Xyl \\
\hline M60 & 4.21 & 7.60 & 2.03 & 1.00 \\
M100 & 4.11 & 2.77 & 1.70 & 1.00 \\
M160 & 3.11 & 2.91 & 1.67 & 1.00 \\
M200 & 5.22 & 9.14 & 1.74 & 1.00 \\
M400 & 4.22 & 4.81 & 1.97 & 1.00 \\
\hline
\end{tabular}

The table shows the molar ratio of each monosaccharide component. Example: M60 is composed of mannose (Man), glucose (Glu), galactose (Gal) and xylose (Xyl), and the molar ratio is $4.21: 7.60: 2.03: 1.00$ which also exerted considerable impact on physicochemical properties and bioactive compounds of YFP powders. Shear breakdown and fragmentation of YFP granules contributed to degree of amorphousness of YFP powders and led to enhanced solubilization during moisture treatment.

\subsection{Bioactive compounds of superfine YFP powder}

Bioactive compounds of YFP powder fraction obtained at variables mesh sizes were analyzed and results are demonstrated in Figure 1 in terms of TPC, TFC, TSC and radical-scavenging activities. As shown in Figure 1, YFP fraction at M100 mesh
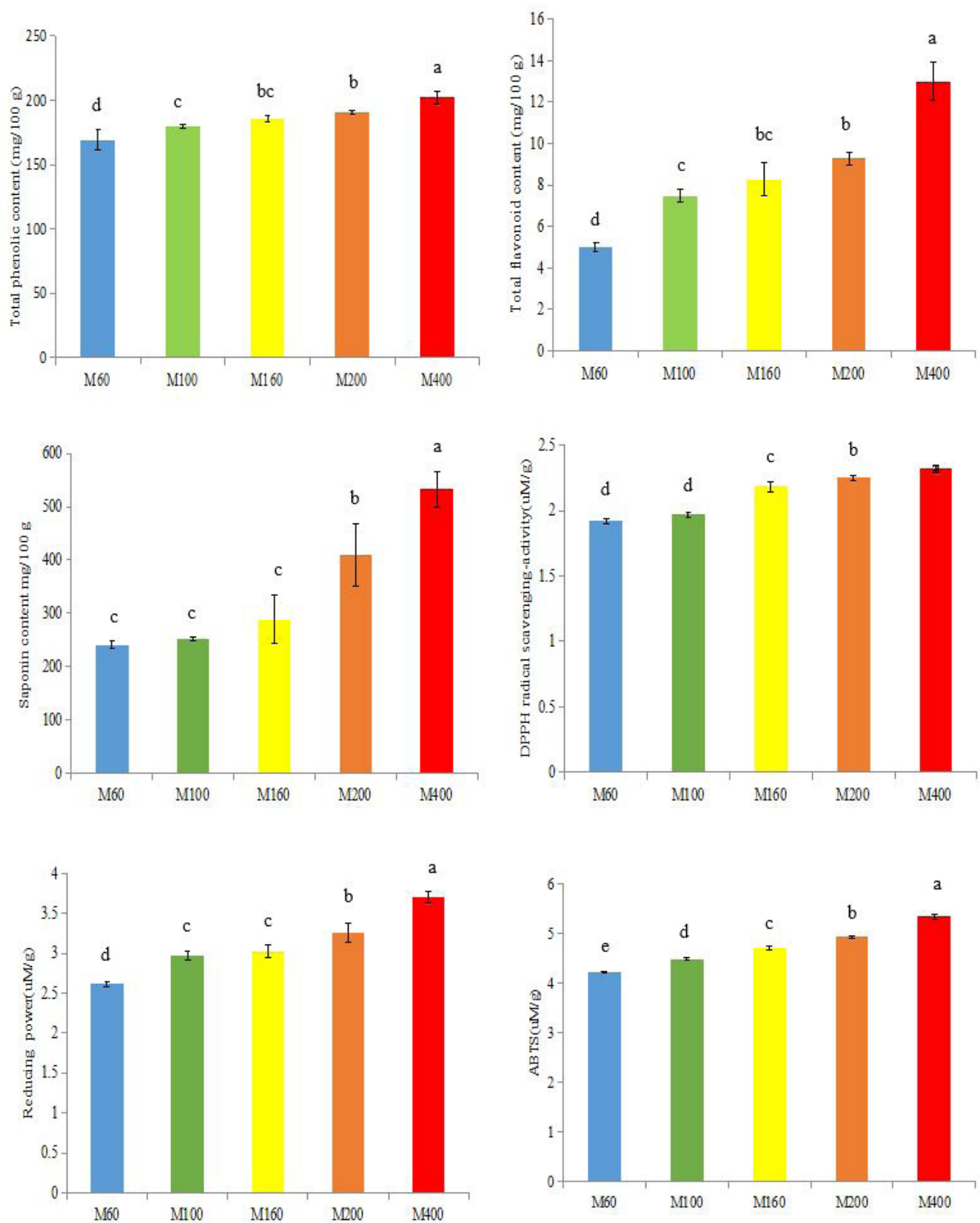

Figure 1. Antioxidant activities of Yam Flour (YF) with different particle size. a-e Means followed by different letters in the same bar represent statistically significant differences $(\mathrm{p}<0.05)$. 
(a)
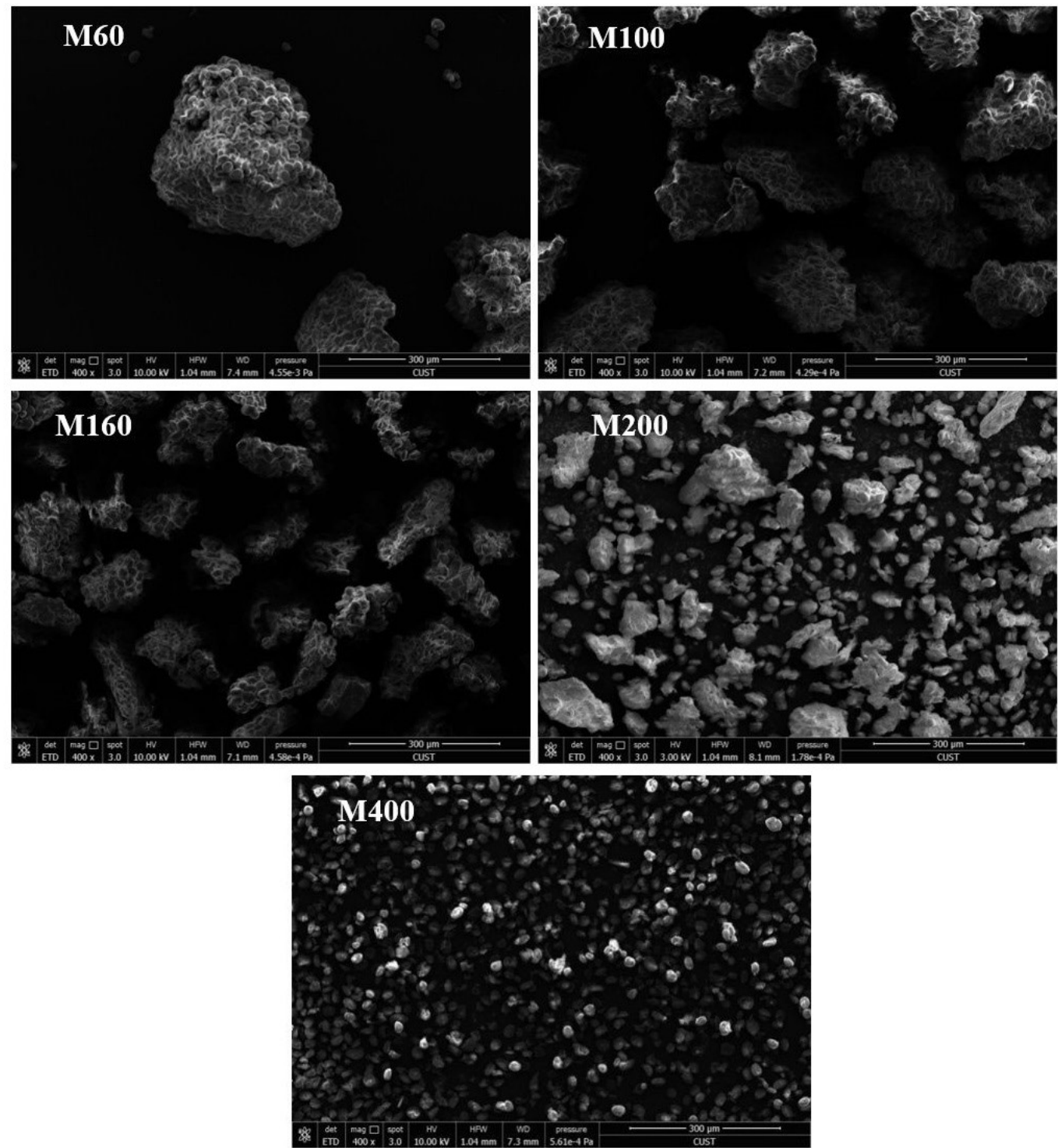

$(\mathbf{b})$

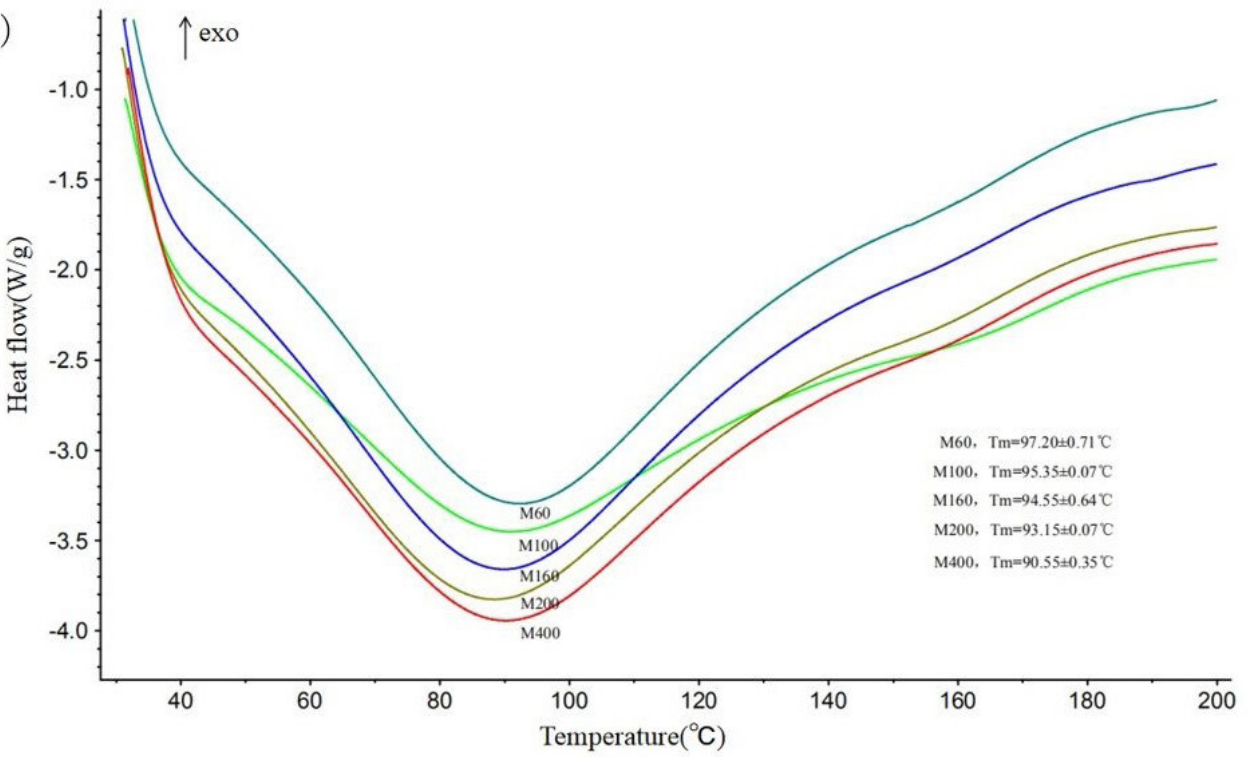

Figure 2. Environmental scanning electron microscopy (ESEM) images (a), DSC curves (b) of Yam Flour (YF) with different particle size. 
size did not show any significant increase in TFC whereas, further rise in mesh sizes and subsequent particle size reduction caused gradual rises in TFC content. TFC content ranged 169.32-202.06 $\mathrm{mg} / 100 \mathrm{~g}$ DW and M400 exhibited the highest TFC content of $202.06 \mathrm{mg} / 100 \mathrm{~g}$ DW. Similar trend was observed in case of TFC which were $5 \mathrm{mg} / 100 \mathrm{~g}$ and $13 \mathrm{mg} / 100 \mathrm{~g}$ DW, respectively in M60 and M400 superfine YFP fractions, respectively. Saponins content were also found in range of 240.01 to $532.52 \mathrm{mg} / 100 \mathrm{~g}$ DW. TSC showed gradually increasingly tendency with corresponding reduction in particle sizes of YFP fractions. Increasing tendencies in TPC, TFC and TSC contents with corresponding reduction in particle sizes might be ascribed to pulverization effect of superfine grinding which caused increased accumulation of free phenolic compounds owing to partial cellular disruption. Similar to phenolic and flavonoid compounds, DPPH, ABTS and FRAP-RSA's were ranged in all YFP superfine fractions as 1.92-2.32, 2.61-3.71 and 4.21-5.34 $\mu \mathrm{M}$ TE/g DW. All RSA's showed increasing trends in gradual manner with corresponding rises in mesh sizes from M60 to M400. It may be implied that findings of this study suggested that bioactive compounds (total phenolics and flavonoid contents) were found to exhibit positive correlation with that of increasing DPPH, ABTS and FRAP-RSA's. When the YFP powder were subjected to grinding at high mesh sizes of M200 and M400, then this led to enhancement in leaching of free phenolic metabolites out of cellular matrices and this might be the probable explanation for increased antioxidant activities of YFP powder fractions. These results were in conformance with the previously reported findings of other studies which implied that structural components of cell wall were strongly influenced by pulverization effect of superfine grinding owing to shear disintegration and disruption of plant cell matrices which consequently led to improved mass transfer and release of bound cell wall phenolic and antioxidant compounds (Zaiter et al., 2016). Similarly, in another study by Zhong et al. (2016), it was implied that superfine grinding led to increased concentrations of bound flavonoids owing to enhanced release from pomegranate peel and exposed surface area. Bound plant metabolites are usually found in vicinity of other plant cellular constituents (cellulose, pectin and organic sugars) bound to antioxidant and phenolic compounds through covalent linkages.

\subsection{Thermal properties}

DSC is useful analytical technique which provides information about material transition characteristics in terms of thermograms showing enthalpy changes brought about by exothermic and endothermic processes. Complex ingredients are usually found in yam composition comprising of lignans, hemicelluloses, xylans, monosaccharides, minerals and proteins. Therefore, excluding phase changes, thermal treatments may also cause thermally-induced modifications in food materials. In Figure 2b, thermograms are shown in terms of DSC curves for all YFP fractions at variable particle sizes. DSC curves evidently showed that all powdered products exhibited recorded heat flow below zero which provides an indication of actual occurrence of endothermic process during initialization of thermal process varying at temperature range of $20-200{ }^{\circ} \mathrm{C}$. Moreover, sharp endothermic peak was found in temperature range from 84 to $87^{\circ} \mathrm{C}$, whereas, increasing tendency in particle size reduction of YFP fractions led to corresponding decreases in peak temperatures. With increases in particle size reduction, significant effect of mesh sizes $(p<0.05)$ were observed in heat flow, however, there may be other potentially influential factors along with particle size reduction which exerted influence on heat flow and thermal properties and need to further explored in future studies. Hence, it may be conclusively ascertained that size reduction resulted in decreased melting point as well as enhanced exposure of biomolecules, such as polysaccharides and points. Similar results were reported by Wu et al. (2021) for superfine Sanchi flower powders.

\section{Conclusions}

This study was carried out to evaluate the effects of superfine grinding at variable mesh sizes on physicochemical, thermal, microstructural attributes, bioactive compounds and radical scavenging activities of yam flour powders. It can be implied that superfine grinding exerted significant influence on these properties and bioactive compounds and relatively brighter powders with reduced degree of redness might be achieved from superfine grinding of YFP. It was also found that WSI and OHC were improved in YFP powders with reduced particle sizes accompanied by lower degree of flowability. Moreover, increasing tendencies in TPC, TFC, TSC contents as well RSA's were observed with corresponding reduction in particle sizes which might be ascribed to pulverization effect of superfine grinding which caused increased accumulation of free phenolic compounds owing to partial cellular disruption. YFP powders exhibit great potential to be employed in manufacturing of food and nutraceutical products as well as potential nutritional regulator as YFP may lead to increased inhibition of free radicals, regulation of oxidative stress and absorption of harmful lipid compounds.

\section{Funding}

This work was supported by Foundation of Innovation and Entrepreneurship Program of college students in Jilin Province (No. 201913706056); Foundation of Ph.D. Research Project, Jilin Medical University (No. JYBS2019010), Jilin Province, China.

\section{References}

Abdul-Hamid, A., \& Luan, Y. S. (2000). Functional properties of dietary fibre prepared from defatted rice bran. Food Chemistry, 68(1), 15-19.

Augusto-Obara, T. R., Oliveira, J. D., Gloria, E. M. D., Spoto, M. H. F., Godoy, K., Vieira, T. M. F. D. S., \& Scheuermann, E. (2019). Benefits of superfine grinding method on antioxidant and antifungal characteristic of Brazilian green propolis extract. Scientia Agrícola, 76(5), 398-404. http://dx.doi.org/10.1590/1678-992x-2018-0056.

Cao, X., Zhang, M., Mujumdar, A. S., Zhong, Q., \& Wang, Z. (2018). Effect of nano-scale powder processing on physicochemical and nutritional properties of barley grass. Powder Technology, 336, 161167. http://dx.doi.org/10.1016/j.powtec.2018.05.054.

Carr, R. L. (1965). Evaluating flow properties of solids. Chemical Engineering, 18, 163-168.

Chen, Y. F., Zhu, Q., \& Wu, S. (2015). Preparation of oligosaccharides from Chinese yam and their antioxidant activity. Food Chemistry, 
173, 1107-1110. http://dx.doi.org/10.1016/j.foodchem.2014.10.153. PMid:25466131.

Eghdami, A., \& Sadeghi, F. (2010). Determination of total phenolic and flavonoids contents in methanolic and aqueous extract of Achillea millefolium. Organic Chemistry Journal, 2, 81-84.

$\mathrm{Hu}$, J., Chen, Y., \& Ni, D. (2012). Effect of superfine grinding on quality and antioxidant property of fine green tea powders. LWT, 45(1), 8-12. http://dx.doi.org/10.1016/j.lwt.2011.08.002.

Huang, X., Dou, J. Y., Li, D., \& Wang, L. J. (2018). Effects of superfine grinding on properties of sugar beet pulp powders. LWT, 87, 203209. http://dx.doi.org/10.1016/j.lwt.2017.08.067.

Jeon, J. R., Lee, J. S., Lee, C. H., Kim, J. Y., Kim, S. D., \& Nam, D. H. (2006). Effect of ethanol extract of dried Chinese yam (Dioscorea batatas) flour containing dioscin on gastrointestinal function in rat model. Archives of Pharmacal Research, 29(5), 348-353. http:// dx.doi.org/10.1007/BF02968583. PMid:16756078.

Jiang, G. H., Nam, S. H., \& Eun, J. B. (2018). Effects of peeling, drying temperature, and sodium metabisulfite treatment on physicochemical characteristics and antioxidant activities of Asian pear powders. Journal of Food Processing and Preservation, 42(2), e13526.

Ju, Y., Xue, Y., Huang, J., Zhai, Q., \& Wang, X. H. (2014). Antioxidant Chinese yam polysaccharides and its pro-proliferative effect on endometrial epithelial cells. International Journal of Biological Macromolecules, 66, 81-85. http://dx.doi.org/10.1016/j.ijbiomac.2014.01.070. PMid:24530337.

Li, G., Guo, W., Gao, X., Wang, Y., \& Sun, S. (2020). Effect of superfine grinding on physicochemical and antioxidant properties of soybean residue powder. Food Science \& Nutrition, 8(2), 1208-1214. http:// dx.doi.org/10.1002/fsn3.1409. PMid:32148826.

Li, L., Zhang, M., \& Bhandari, B. (2019a). Influence of drying methods on some physicochemical, functional and pasting properties of Chinese yam flour. $L W T, 111,182-189$. http://dx.doi.org/10.1016/j. lwt.2019.05.034.

Li, T., Yang, Y., Chen, L., \& Yang, W. (2019b). Effects of Grinding Methods on Physicochemical Properties of Crude Polysaccharides from Phellinus baumii. In Y. Wang (Ed.), 2018 International Seminar on Food Safety and Environmental Engineering (FSEE 2018). Guangzhou: The Committee of FSEE 2018. http://dx.doi. org/10.1051/e3sconf/20197802004.

Meng, Q., Chen, F., Xiao, T., \& Zhang, L. (2019). Superfine grinding of Dendrobium officinale: the finer the better? International Journal of Food Science \& Technology, 54(6), 2199-2208. http://dx.doi. org/10.1111/ijfs.14129.

Muttakin, S., Kim, M. S., \& Lee, D. U. (2015). Tailoring physicochemical and sensorial properties of defatted soybean flour using jet-milling technology. Food Chemistry, 187, 106-111. http://dx.doi.org/10.1016/j. foodchem.2015.04.104. PMid:25977004.
Park, S. J., RnD, C. C. F., Kim, A. Y., Lee, H. S., Kim, B. Y., \& Baik, M. Y. (2012). Effects of puffing process on the saponin components in Platycodon grandiflorus (jacqin) A. De Candle. Food Engineering Progress, 16(2), 164-171.

Phat, C., Li, H., Lee, D. U., Moon, B., Yoo, Y. B., \& Lee, C. (2015). Characterization of Hericium erinaceum powders prepared by conventional roll milling and jet milling. Journal of Food Engineering, 145, 19-24.

Ramachandraiah, K., \& Chin, K. B. (2017). Impact of drying and micronization on the physicochemical properties and antioxidant activities of celery stalk. Journal of the Science of Food and Agriculture, 97, 4539-4547.

Quispe-Condori, S., Saldaña, M. D., \& Temelli, F. (2011). Microencapsulation of flax oil with zein using spray and freeze drying. LWT, 44(9), 1880-1887. http://dx.doi.org/10.1016/j.lwt.2011.01.005.

Shujun, W., Jinglin, Y., Hongyan, L., \& Weiping, C. (2008). Characterisation and preliminary lipid-lowering evaluation of starch from Chinese yam. Food Chemistry, 108(1), 176-181. http://dx.doi.org/10.1016/j. foodchem.2007.10.059. PMid:26054279.

Wu, Z., Ameer, K., \& Jiang, G. (2021). Effects of superfine grinding on the physicochemical properties and antioxidant activities of Sanchi (Panax notoginseng) flower powders. Journal of Food Science and Technology, 58(1), 62-73. http://dx.doi.org/10.1007/s13197-02004514-2. PMid:33505052.

Yang, W., Wang, Y., Li, X., \& Yu, P. (2015). Purification and structural characterization of Chinese yam polysaccharide and its activities. Carbohydrate Polymers, 117, 1021-1027. http://dx.doi.org/10.1016/j. carbpol.2014.09.082. PMid:25498730.

Zaiter, A., Becker, L., Karam, M. C., \& Dicko, A. (2016). Effect of particle size on antioxidant activity and catechin content of green tea powders. Journal of Food Science and Technology, 53(4), 20252032. http://dx.doi.org/10.1007/s13197-016-2201-4. PMid:27413230.

Zhao, X., Du, F., Zhu, Q., Qiu, D., Yin, W., \& Ao, Q. (2010). Effect of superfine pulverization on properties of Astragalus membranaceus powder. Powder Technology, 203(3), 620-625. http://dx.doi. org/10.1016/j.powtec.2010.06.029.

Zhao, X., Zhu, H., Chen, J., \& Ao, Q. (2015b). FTIR, XRD and SEM analysis of ginger powders with different size. Journal of Food Processing and Preservation, 39(6), 2017-2026. http://dx.doi.org/10.1111/jfpp.12442.

Zhao, X., Zhu, H., Zhang, G., \& Tang, W. (2015a). Effect of superfine grinding on the physicochemical properties and antioxidant activity of red grape pomace powders. Powder Technology, 286, 838-844. http://dx.doi.org/10.1016/j.powtec.2015.09.025.

Zhong, C., Zu, Y., Zhao, X., Li, Y., Ge, Y., Wu, W., Zhang, Y., Li, Y., \& Guo, D. (2016). Effect of superfine grinding on physicochemical and antioxidant properties of pomegranate peel. International Journal of Food Science \& Technology, 51(1), 212-221. http://dx.doi. org/10.1111/ijfs.12982. 